\title{
Analysis of Arc Tube Properties by Degradation in Ceramic Metal Halide Lamp
}

\author{
Jong-Kyung Yang ${ }^{\dagger}$, Hyeok-Jin Jang** and Dae-Hee Park*
}

\begin{abstract}
To clarify the relations of optical properties to the main factors responsible for the loss and damage of luminous efficacy, a $20 \mathrm{~min}$ turn-on/turn-off test for 2,000 h for a ceramic metal halide lamp is conducted. The corrosion rates of the arc tube wall and electrode are estimated based on thermal stress. Wall blackening is attributed to the tungsten being transported from the hot electrode tips to the relatively cold arc tube wall. Furthermore, the grain boundaries of the arc tube are changed by the degradation. Distortion of the electrode is observed, and the ignition and the driving voltage of the load both increase. Finally, the color rendering index and the color coordinates are changed after the degradation. The luminous flux and the intensity of the luminous distribution are decreased significantly.
\end{abstract}

Keywords: Ceramic metal halide, Degradation, Arc tube, Wall blackening, Discharge

\section{Introduction}

A ceramic metal halide lamp usually contains mercury as the buffer gas and rare earth additives that radiate very efficiently in the visible spectrum. While applying an ignition voltage of $4 \mathrm{kV}$ to the arc-tube, thermal and optical energy is generated by strong plasma convection. Thermal energy and optical energy are emitted to the outside through a ceramic arc tube made of $\mathrm{Al}_{2} \mathrm{O}_{3}$.

However, plasma convection in an arc tube at high pressure and temperature results in a loss of tungsten, iodine composite, and rare earth elements, as well as the corrosion of the arc tube by chemical recombination [1]-[3].

Furthermore, because of the corrosion of the electrode and the arc tube, the initial arc shape changes accordingly with the change in the magnetic properties. Ultimately, this phenomenon leads to the damage of the discharge lamp and to inferior performance.

In this study, to clarify the relation of optical properties with the main factors responsible for the loss and damage of luminous efficacy, we conduct a 20 min turn-on/turn-off test for $2,000 \mathrm{~h}$ on a ceramic metal halide lamp.

\section{Theory and Experimental Setup}

\subsection{Discharge Theory of Ceramic Metal Halide Lamp}

A ceramic metal halide lamp was used for replacing the ceramic materials from quartz in an arc tube. The structure

$\dagger \quad$ Corresponding Author: Dept. of Electrical Materials Engineering, Wonkwang University, Korea. (duck2214@wonkwang.ac.kr)

* Dept. of Electrical and Information Engineering, Wonkwang University, Korea. (parkdh@wonkwang.ac.kr)

** R\&BD, KILT, Korea. (jdk011@naver.com)

Received: September 2, 2010; Accepted: December 8, 2010 of the discharge is shown in Fig. 1. When high ignition voltage is applied through two electrodes, the initial discharge process of the ceramic metal halide lamp involves a glow discharge for a few microseconds $(\mu \mathrm{s})$ after the breakover of the buffer gas.

As the temperature of the arc tube gradually increases, the melting and evaporation of the metal halide begins and moves to the center of the arc tube. The metal and halogen atoms then become separated. The arc is formed from the emitted light caused by the collision between the metal elements and the electrons [6].

Fig. 2 shows the V-I transition curve of the ceramic metal halide lamp.

The power of the lamp increases with an increase in voltage in the glow-to-arc transition state, in which the metal and the halogen elements are recombined at a cold spot. Thereafter, the lamp enters thermal equilibrium state from arc discharge state, and the current becomes constant. When the on-off test is carried out continuously, high current and voltage are required for ignition, and the stress is accelerated by a change in the inner pressure.

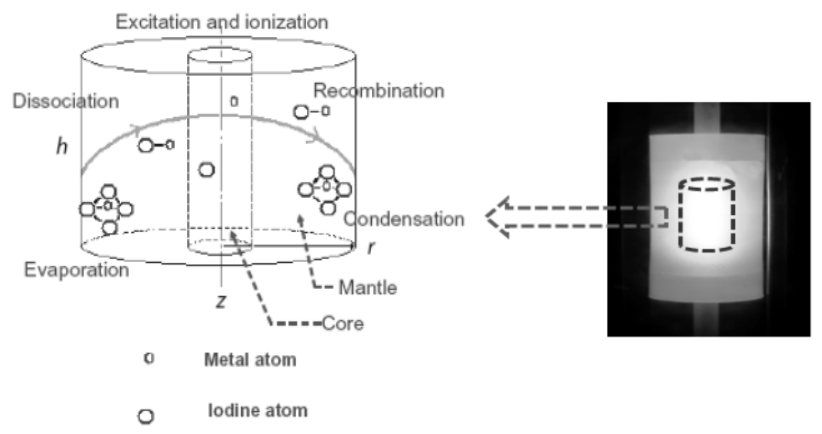

Fig. 1. Discharge phenomenon inside cylindrical ceramic arc tube. 


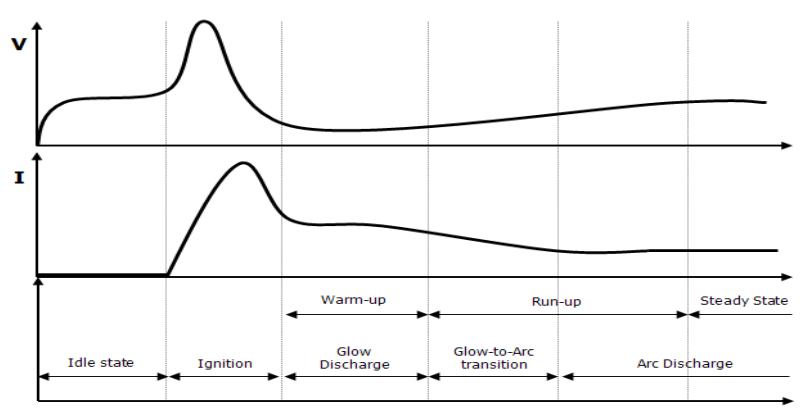

Fig. 2. V-I curve according to discharge process in ceramic metal halide lamp.

\subsection{Theory of Wall Blackening Phenomenon}

Fig. 3 illustrates the wall blackening phenomenon in the arc tube. Wall blackening is caused by a thin layer of electrode material being deposited on the inner wall of the discharge tube over its lifetime. The electrode is designed for nominal lamp power; thus, deviations in lamp power caused by under-voltage or over-voltage of the main power supply cause this blackening process [4].

The discharge and intensive ion bombardment caused by the process severely overheat the electrodes; therefore, tungsten and other electrode materials become splattered on the internal bulb walls of the arc chamber, accelerating the wall blackening phenomenon.
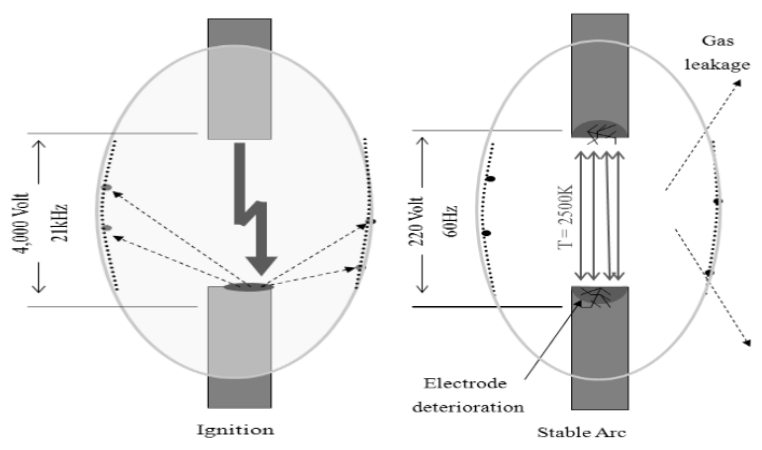

Fig. 3. Illustration the theory of wall blackening.

\subsection{Experimental Method and Equipment}

Using a $20 \mathrm{~min}$ on/off test, a ceramic metal halide lamp was evaluated for 2,000 $\mathrm{h}$ under the condition of accelerated aging based on the RSC0085 High Intensity Discharge Lamp (HID) reliability evaluation criterion, as shown in Fig. 4. Twenty minutes was set as the on/off time, by considering the stable state time and restart-discharge condition. Degradation time can be estimated at approximately $5,000 \mathrm{~h}$ using the relation between the rate of flickering and the lifetime of the lamp. A magnetic ballast of $150 \mathrm{~W}$ was used at an ambient temperature of $25^{\circ} \mathrm{C}$ [7].

Furthermore, an integrating sphere (PMS-50, EVERFINE Corp.) was used for estimating the optical

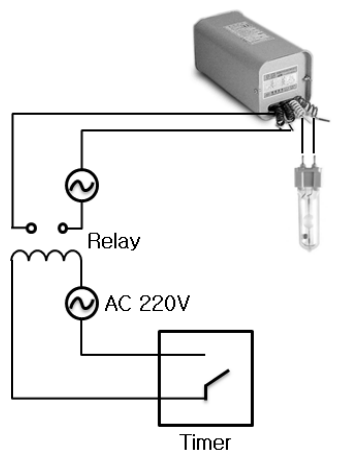

Fig. 4. Experimental setup.

properties of the sample. An X-ray non-destructive system (SMX-225CT Special, Shimadzu Corp.) and an FE-SEM (S-4800, Hitachi Corp.) were used for analyzing the structural characteristics.

\section{Results and Discussion}

\subsection{Wall Blackening Phenomenon in Arc Tube and Degradation in Electrode and Surface}

Fig. 5 shows the blackening of the arc tube and the deterioration of the surface of the electrode caused by the accelerated degradation test.

In the arc tube, wall blackening is caused by the transportation of tungsten from the hot electrode tips to the relatively cold arc tube wall. The deteriorating translucence is further attributed to the formation of a $3 \mathrm{Dy}_{2} \mathrm{O}_{3}-5 \mathrm{Al}_{2} \mathrm{O}_{3}$ garnet, the thermal etching of alumina, and the abnormal growth of the alumina grains [3].

Fig. 6 shows the growth of the electrode degradation. The tungsten shifted to the arc tube wall from the electrode, as shown in Tables 1 and 2. As shown in Equation (1), tungsten combined with oxygen and iodine at a high temperature, and was deposited as $\mathrm{WO}_{2} \mathrm{I}_{2}$ near the wall. In this situation, regeneration does not occur in the system when regeneration and deposition are repeated, causing the wall blackening and degradation of the electrode [3].

$$
\begin{aligned}
& \mathrm{W}(\mathrm{g})+2 \mathrm{O}(\mathrm{g})+2 \mathrm{I}(\mathrm{g}) \text { (at high temperature) } \\
& \qquad \leftrightarrow \mathrm{WO}_{2} \mathrm{I}_{2} \text { (near the wall) }
\end{aligned}
$$

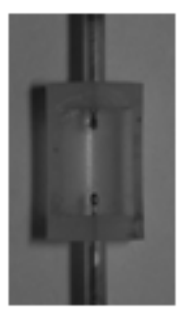

(a) Initial

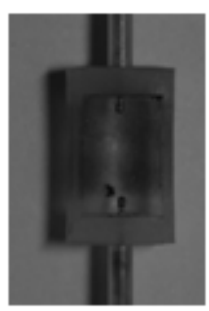

(b) After 2,000 h
Fig. 5. Wall blackening phenomena in arc tube. 


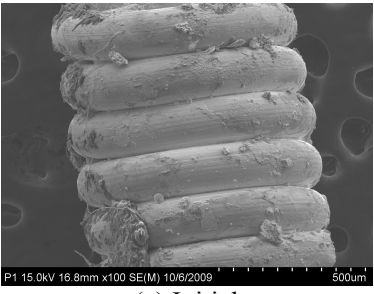

(a) Initial

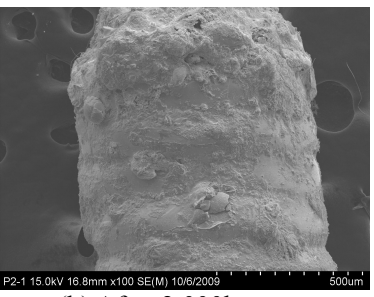

(b) After 2,000h
Fig. 6. FE-SEM of electrode changed by degradation.

Table 1. Surface components in electrode

\begin{tabular}{c|c|c|c|c|c}
\hline \multicolumn{3}{c|}{$\begin{array}{c}\text { Initial surface components of elec- } \\
\text { trode [\%] }\end{array}$} & \multicolumn{3}{|c}{$\begin{array}{r}\text { Surface components of electrode } \\
\text { after 2,000 h [\%] }\end{array}$} \\
\hline Element & Weight & Atomic & Element & Weight & Atomic \\
\hline $\mathrm{C}$ & 8.22 & 39.88 & $\mathrm{C}$ & 9.64 & 29.33 \\
\hline $\mathrm{O}$ & 9.14 & 33.27 & $\mathrm{O}$ & 20.05 & 45.83 \\
\hline $\mathrm{I}$ & 6.41 & 2.94 & $\mathrm{Na}$ & 6.97 & 11.09 \\
\hline $\mathrm{W}$ & 68.59 & 21.73 & $\mathrm{I}$ & 12.96 & 3.73 \\
\hline $\mathrm{Tl}$ & 7.64 & 2.18 & $\mathrm{~W}$ & 50.38 & 10.02 \\
\hline Total & 100.00 & & Total & 100.00 & \\
\hline
\end{tabular}

Table 2. Surface components in arc tube

\begin{tabular}{c|c|c|c|c|c}
\hline \multicolumn{3}{c|}{$\begin{array}{c}\text { Initial surface components of arc } \\
\text { tube [\%] }\end{array}$} & \multicolumn{3}{|c}{$\begin{array}{r}\text { Surface components of arc tube } \\
\text { after 2,000 h [\%] }\end{array}$} \\
\hline Element & $\begin{array}{c}\text { Molecular } \\
\text { Weight }\end{array}$ & $\begin{array}{c}\text { Atomic } \\
\text { Weigh }\end{array}$ & Element & $\begin{array}{c}\text { Molecular } \\
\text { Weight }\end{array}$ & $\begin{array}{c}\text { Atomic } \\
\text { Weigh }\end{array}$ \\
\hline $\mathrm{C}$ & 4.68 & 7.61 & $\mathrm{C}$ & 7.52 & 17.15 \\
\hline $\mathrm{O}$ & 48.58 & 59.29 & $\mathrm{O}$ & 29.75 & 50.96 \\
\hline $\mathrm{Al}$ & 45.32 & 32.80 & $\mathrm{Na}$ & 1.85 & 2.20 \\
\hline $\mathrm{Zr}$ & 1.42 & 0.30 & $\mathrm{Al}$ & 23.47 & 23.84 \\
\hline & & & $\mathrm{I}$ & 4.08 & 0.88 \\
\hline & & & $\mathrm{W}$ & 33.33 & 4.97 \\
\hline Total & 100.00 & & Total & 100.00 & \\
\hline
\end{tabular}

Fig. 7 shows the change of grain boundaries in the arc tube because of the degradation. Transmittance is decreased by the wall blackening and the scattering of residual porosity. Moreover, at the one-week mark, cracks appear on arc tube wall from thermal stress corrosion in some samples [5].

Fig. 8 shows the distortion of the electrode in the arc tube after 2,000 h. Rare earth elements, which are additives in the arc tube, accumulate through the chemical reaction between the electrode and the tube, as shown in Equations (2) and (3).

The thermal expansion coefficient of the electrode changes from that of the bond material because of combination with the additive. As a result, the electrode becomes distorted, and the ignition and driving voltage of load increase from 82.2 to $101 \mathrm{~V}$. These changes of voltage affect the arc formation.

$$
\mathrm{REI}_{3}+\mathrm{Al}_{2} \mathrm{O}_{3} \Leftrightarrow \mathrm{REAlO}_{3}+\mathrm{AlI}_{3}
$$

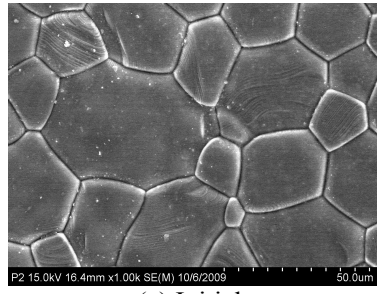

(a) Initial

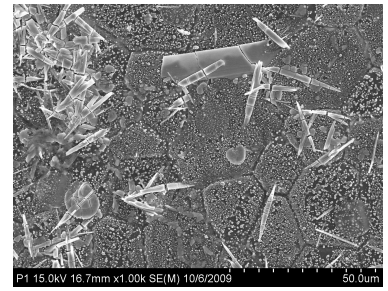

(b) After 2,000h
Fig. 7. FE-SEM of arc tube changed by degradation.

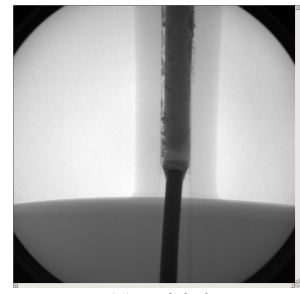

(a) Initial

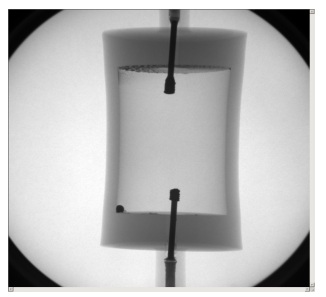

(b) After 2,000h
Fig. 8. Wall blackening phenomenon in the arc tube.

$$
\mathrm{Al}_{2} \mathrm{O}_{3}+\mathrm{AlI}_{3} \Rightarrow 3 \mathrm{AlOI}_{3}
$$

\section{RE: Rare earth iodides}

\subsection{Change in Optical Properties of Arc Tube}

Metal halide compounds and rare earth metals are added to the ceramic metal halide lamp in order to improve the efficiency and the color rendering index. The composition of additives can be identified by using spectrum analysis, as shown in Fig. 9. In the tested lamp, the metal halide pill consists of the NaI-Tll-DyI3-CeI3 compound. The Dy and Ce contents were reduced with a spectrum line having a wavelength of 400-450 $\mathrm{nm}$, depending upon the degradation.

Fig. 10 shows the change in the color rendering index and the color coordinates after degradation. The color rendering index of the lamp was slightly lowered, from 88.7 to 87.8 , and R9 was reduced distinctively. Therefore, the color temperature also changed from 4,200 to $3,143 \mathrm{~K}$.

The luminous flux changed from the initial value of 9,006.5 to 5,993.9 $\mathrm{lm}$ after $2,000 \mathrm{~h}$ because of the internal loss and structural changes (i.e., wall blackening). Fur-

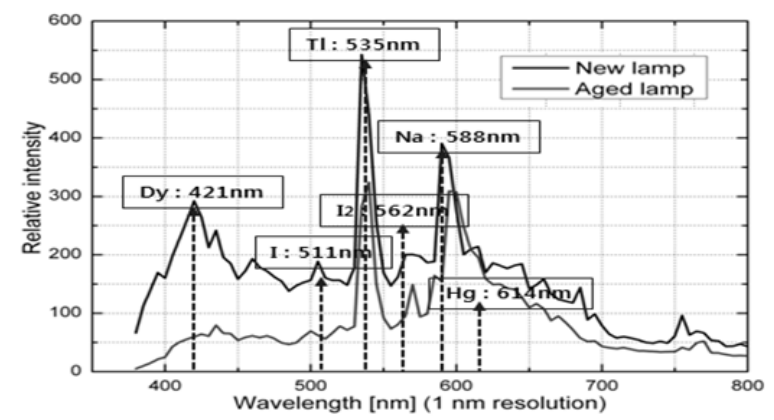

Fig. 9. Spectra of estimated change in additives in arc tube. 


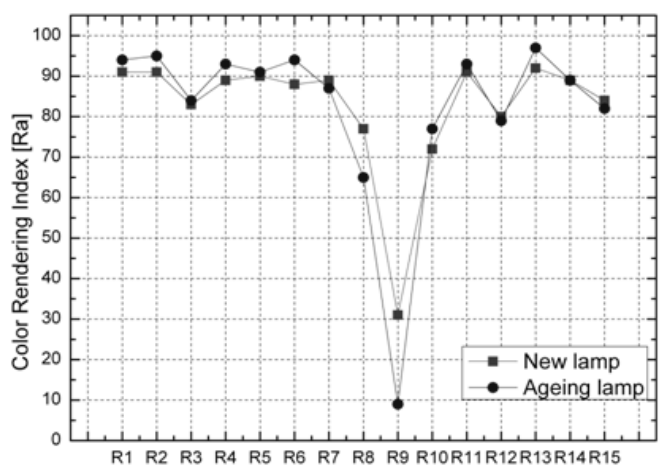

(a) Color rendering index
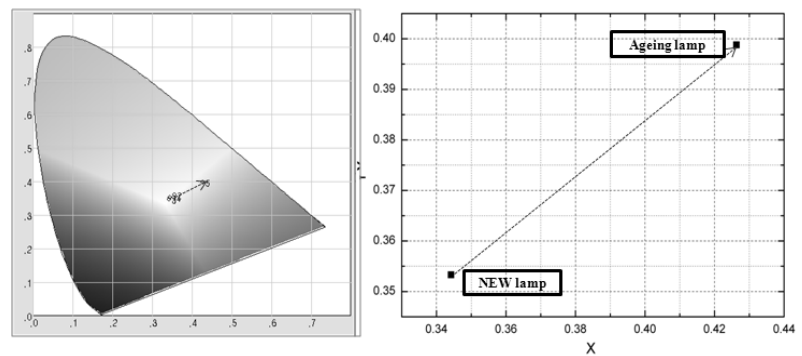

(b) Color coordinates

Fig. 10. Change in color rendering index and color coordinates.

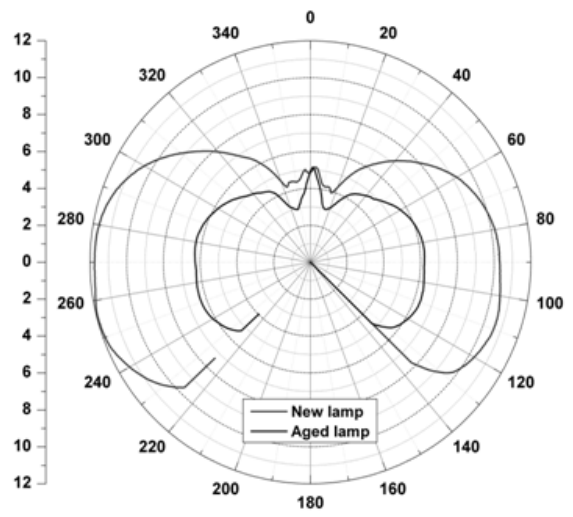

Fig. 11. Change of luminous distribution.

thermore, the intensity of the luminous distribution decreased, as shown in Fig. 11.

\section{Conclusion}

In this study, in order to clarify the relation of optical properties with the main factors responsible for the loss and damage of luminous efficacy, a $20 \mathrm{~min}$ turn-on/turn-off test was conducted for $2,000 \mathrm{~h}$ on a ceramic metal halide lamp. As a result, the following conclusions were drawn:

1. The corrosion of the arc tube wall and electrode is attributed to the thermal stress and wall blackening be- cause of the transportation of tungsten from the hot electrode tips to the relatively cold arc tube wall.

2. Grain boundaries of the arc tube are changed by degradation. Moreover, the transmittance is decreased by the wall blackening and scattering of the residual porosity

3. The thermal expansion coefficient of the electrode changes from that of the bond material because it combines with the additive. As a result, the electrode becomes distorted, and the ignition and driving voltages of the load increase.

4. Finally, the color rendering index and the color coordinates are changed after the luminous flux becomes degraded, and the intensity of the luminous distribution decreases significantly.

\section{Acknowledgment}

This work was financially supported by wonkwang university in 2010

\section{References}

[1] W. van Erk, "Transport processes in metal halide gas discharge lamps”, Pure Appl.Chem., Vol. 72, No. 11, pp. 2159-2166, 2000

[2] W. P. Lapatovich, "Metal-halide lamp design: atomic and molecular data needed", Phys. Scr T134, (014024), 2009

[3] H. Honda, A. Itoh and S, "Analysis of factors affecting the lumen maintenance of ceramic metal halide lamps", Journal of the Illuminating Engineering Institute of Japan, Vol. 87, No. 11, pp. 898-911, 2003.

[4] Y. Shata, "Study on the wall blackening of a high intensity discharge lamp”, J. Plasma Fusion Res. Series, Vol. 8, pp. 1313-1316, 2009.

[5] Theo. G. M. M. Kappen, "Status quo of ceramic material for metal halide discharge lamps", J. Phys. D: Appl. Phys., Vol. 38, pp. 3033-3039, 2005.

[6] B. Preston and E.C. Odell, "Metal halide lamps", Lamp and Lighting, pp. 263-280, 1997.

[7] Reliability evaluation criterion RS C 0085, "High pressure Discharge lamp”, 2007

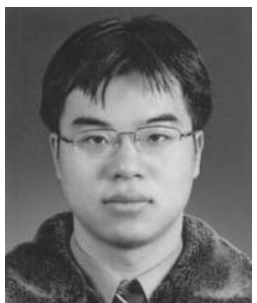

Jong-Kyung Yang received his B.S. and M.S. degrees in Electrical Materials Engineering from Wonkwang Univ. in 2001 and 2005, respectively. He is currently pursuing is a Ph.D. in the Department of Electrical Materials, Wonkwang University. His main research interests are thermal and optical design of LED lighting, ceramic metal halide lamps, and analysis of plasma. 


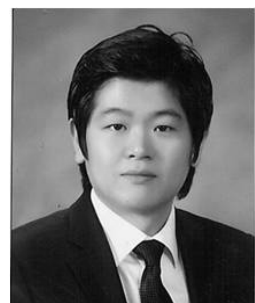

Hyeok-Jin Jang received his B.S. and M.S. degrees in Electrical Materials Engineering from Wonkwang Univ. in 2005 and 2008 . He is currently working for the Korea Institute of Lighting Technology.

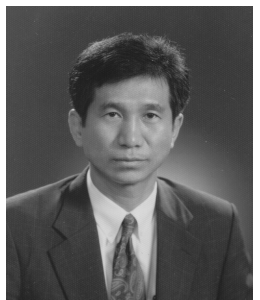

Dae-Hee Park received his B.S. and M.S. degrees in Electrical Engineering from Hanyang University, Seoul, Korea in 1979 and 1983, respectively. He received his Ph.D. degree from Osaka University, Osaka, Japan in 1989. He worked at the LG Cable Research Institute as a Senior Researcher from 1979 to 1991. he then joined the School of Electrical Electronics and Information Engineering at Wonkwang University, where he is currently employed as a Professor. He has also worked as Director of the "Center for Advanced Electric Application" at Wonkwang University from 2004. He was at Michigan state university in the USA as a Visiting Professor from 1999 to 2000. Since 2009, he has acted as Chairman of the College of Engineering, Wonkwang University. His main research interests are in the areas of insulating and dielectric materials, new lighting, sources, and discharge lighting. He is a member of the Korean IEE, Korean IEEME, and IEE Japan. 